GRADIATION\&APPLICATIONS

ISSN 2466-4294 (online) | rad-journal.org

Vol. 2 | Issue 3 | pp. $200-203,2017$

doi: 10.21175/RadJ.2017.03.040

Original research paper

\title{
ESTIMATION OF MEAN GLANDULAR DOSE IN MAMMOGRAPHY USING VOXEL PHANTOM AND MONTE CARLO SIMULATION*
}

\author{
Katarina Karadžićc ${ }^{* *}$, Vuk Karadžić \\ ${ }^{1}$ School of Electrical Engineering, University of Belgrade, Serbia \\ ${ }^{2}$ School of Medicine, University of Belgrade, Serbia
}

\begin{abstract}
Mammography presents one of the most precise methods for detection of irregularities inside the breast. Its most important function is discovering diseases like cancer at an early phase. Although mammography uses a low dose $x$-ray system, the examination still poses certain risk for a patient. Mean glandular dose gives the best representation of risk involved for a patient undergoing mammography examination. In this study, we estimated adipose, glandular and total dose to the breast using Monte Carlo simulations. For this purpose, we designed a voxel breast phantom. Simulations were performed using MCNPX code. Verification of phantom design and simulations was done by comparing the results with those published in similar studies.
\end{abstract}

Key words: Mean glandular dose, mammography, voxel phantom, MCNP

\section{INTRODUCTION}

Mammography is an imaging technique used for the early detection of breast cancer, as well as the detection and diagnosis of cancer during different phases of the disease. Various tissues of the breast have similar attenuation coefficients leading to the use of low energy $x$-rays in order to provide the sufficient contrast in the image. Breast cancer is highly treatable if caught early, with an estimation of reduction in breast cancer mortality of up to 30\% [1]. National screening programs are developed worldwide in which a large part of population undergoes periodic mammography examination. Since x-rays are ionizing radiation, there is a certain risk of inducing cancer to the patients and there is a need to prudently monitor the radiation dose from breast cancer screening.

The mean glandular dose (MGD) provides the best indicator of the risk to the patient from a mammographic examination, because it is commonly assumed that the cancer risk is linearly related to the dose and the breast cancers arise in the glandular dose. Mean glandular dose cannot be measured directly. It can either be calculated using simple measurements and lookup tables [2]-[3]. Another way to estimate the mean glandular dose is the use of Monte Carlo simulations [4] - [13].

The particle radiation transport code MCNP (Monte Carlo N Particle) [14] is a general-purpose three-dimensional simulation tool that transports 37 different particle types over a broad range of energies. Its application includes criticality calculations, shielding, dosimetry, detector response and many others. MCNP contains numerous tallies: surface current and flux (track length), point or ring detectors, particle heating, pulse height tally for energy or charge deposition, mesh tallies and radiography tallies.

In this study, we designed a voxel breast phantom in order to estimate the mean glandular and adipose dose to the breast under simple irradiation conditions using Monte Carlo simulations.

\section{MATERIALS AND METHODS}

\section{An Estimation of $M G D$}

The mean glandular dose is the average dose to the glandular tissue in the breast, which is a homogenous combination of adipose and glandular tissue. The ratio of glandular tissue to the breast tissue by weight is denoted as glandularity $g$. The portion of the absorbed energy in the breast tissue due to the glandular tissue $\mathrm{G}$ [4] is:

$$
G=\frac{g\left(\frac{\mu_{e n}}{\rho}\right)_{g}}{g\left(\frac{\mu_{e n}}{\rho}\right)_{g}+(1-g)\left(\frac{\mu_{e n}}{\rho}\right)_{a}}
$$

where $\rho$ is the density of breast tissue based on glandularity given by:

\footnotetext{
* The paper was presented at the Fifth International Conference on Radiation and Applications in Various Fields of Research (RAD 2017), Budva, Montenegro, 2017.

kkatrinari@yahoo.com
} 
K. Karadžić, V. Karadžić, Estimation of mean glandular dose in mammography..., Rad. Applic., 2017, 2, 3, 200-203

$$
\rho=\frac{\rho_{a} \rho_{g}}{g \rho_{a}+(1-g) \rho_{g}}
$$

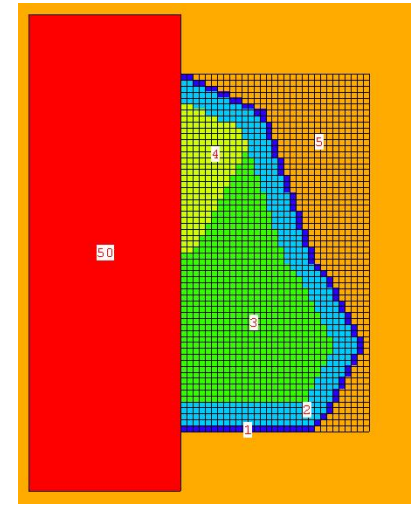

Figure 1. Voxel breast phantom for MLO view
MDG can be calculated from the absorbed dose distribution $\mathrm{D}(\mathrm{E})$, which can be obtained using F6 tally:

$$
M G D=\int D(E) G(E) d E
$$

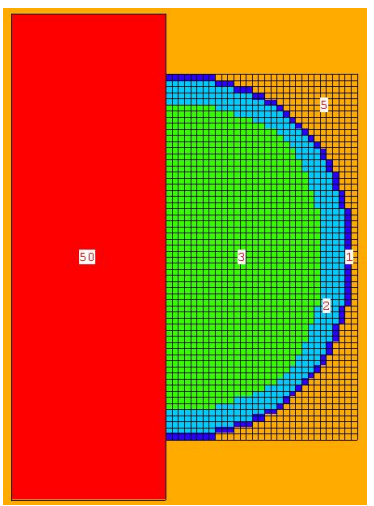

Figure 2. Voxel breast phantom for $\mathrm{CC}$ view

Table 1. MGD in mGy/mGy for different tube voltages, glandular ratios and

\begin{tabular}{|c|c|c|c|c|c|c|c|c|c|c|c|c|}
\hline Anode/Filter & \multicolumn{12}{|c|}{$\mathrm{Mo} / 30 \mu \mathrm{m} \mathrm{Mo}$} \\
\hline Glandularity & \multicolumn{4}{|c|}{0.25} & \multicolumn{4}{|c|}{0.50} & \multicolumn{4}{|c|}{0.75} \\
\hline \multirow{2}{*}{$\begin{array}{c}\text { Tube voltage } \\
(\mathrm{kV})\end{array}$} & \multicolumn{4}{|c|}{ Angle $\left({ }^{\circ}\right)$} & \multicolumn{4}{|c|}{ Angle $\left({ }^{\circ}\right)$} & \multicolumn{4}{|c|}{ Angle $\left({ }^{\circ}\right)$} \\
\hline & 30 & 45 & 60 & 90 & 30 & 45 & 60 & 90 & 30 & 45 & 60 & 90 \\
\hline 25 & 0.026 & 0.033 & 0.051 & 0.045 & 0.055 & 0.061 & 0.095 & 0.083 & 0.078 & 0.086 & 0.133 & 0.117 \\
\hline 28 & 0.029 & 0.034 & 0.055 & 0.045 & 0.054 & 0.063 & 0.102 & 0.085 & 0.076 & 0.089 & 0.144 & 0.119 \\
\hline 29 & 0.032 & 0.034 & 0.053 & 0.046 & 0.055 & 0.064 & 0.100 & 0.085 & 0.078 & 0.090 & 0.140 & 0.120 \\
\hline 30 & 0.031 & 0.035 & 0.054 & 0.046 & 0.058 & 0.065 & 0.100 & 0.085 & 0.081 & 0.091 & 0.141 & 0.120 \\
\hline 32 & 0.031 & 0.035 & 0.053 & 0.046 & 0.058 & 0.066 & 0.100 & 0.086 & 0.081 & 0.093 & 0.140 & 0.121 \\
\hline
\end{tabular}
angles of projections for MLO view for Mo/Mo anode/filter

Table 2. MGD in mGy/mGy for different tube voltages, glandular ratios and

\begin{tabular}{|c|c|c|c|c|c|c|c|c|c|c|c|c|}
\hline Anode/Filter & \multicolumn{12}{|c|}{$\mathrm{Mo} / 25 \mu \mathrm{m} \mathrm{Rh}$} \\
\hline Glandularity & \multicolumn{4}{|c|}{0.25} & \multicolumn{4}{|c|}{0.50} & \multicolumn{4}{|c|}{0.75} \\
\hline \multirow{2}{*}{$\begin{array}{c}\text { Tube voltage } \\
(\mathrm{kV})\end{array}$} & \multicolumn{4}{|c|}{ Angle $\left({ }^{\circ}\right)$} & \multicolumn{4}{|c|}{ Angle $\left({ }^{\circ}\right)$} & \multicolumn{4}{|c|}{ Angle $\left({ }^{\circ}\right)$} \\
\hline & 30 & 45 & 60 & 90 & 30 & 45 & 60 & 90 & 30 & 45 & 60 & 90 \\
\hline 25 & 0.031 & 0.035 & 0.052 & 0.046 & 0.058 & 0.065 & 0.097 & 0.086 & 0.081 & 0.092 & 0.137 & 0.121 \\
\hline 28 & 0.036 & 0.036 & 0.052 & 0.046 & 0.066 & 0.067 & 0.097 & 0.086 & 0.094 & 0.094 & 0.137 & 0.122 \\
\hline 29 & 0.036 & 0.036 & 0.053 & 0.046 & 0.068 & 0.067 & 0.099 & 0.086 & 0.095 & 0.095 & 0.140 & 0.122 \\
\hline 30 & 0.036 & 0.036 & 0.054 & 0.046 & 0.067 & 0.068 & 0.102 & 0.087 & 0.094 & 0.096 & 0.143 & 0.122 \\
\hline 32 & 0.035 & 0.037 & 0.051 & 0.046 & 0.066 & 0.068 & 0.095 & 0.087 & 0.093 & 0.096 & 0.134 & 0.122 \\
\hline
\end{tabular}
angles of projections for MLO view for Mo/Rh anode/filter

\section{$B$ Voxel phantom}

Two voxel breast phantoms were designed in this work, one for the mediolateral oblique (MLO) view (Figure 1) and one for the craniocaudal (CC) view (Figure 2). Voxel phantoms were designed lattice card. When used in a MCNP input file, the lattice card creates a regular grid within the problem geometry. Each grid location is referred to as an individual element or voxel and each voxel is associated with a tissue type. Three parameters were used to define both phantoms: chest wall to nipple distance (CND), compressed breast thickness (CBT) and glandular ratio (g).

For the MLO phantom CND was $6 \mathrm{~cm}$ and CBT was $5 \mathrm{~cm}$. Top layer was skin of $0.2 \mathrm{~cm}$ thickness. Beneath it was layer of adipose tissue $0.8 \mathrm{~cm}$ thick. These two layers surround breast tissue and pectoral muscle. To include backscatter, patient's body was modeled with parallelepiped with dimensions $6 \times 16 \times 7 \mathrm{~cm}$. Voxel size was $0.2 \times 0.2 \times 0.2 \mathrm{~cm}$.

The $\mathrm{CC}$ view phantom is a semi-circular disc. Around the breast tissue, there is a $0.8 \mathrm{~cm}$ thick layer of adipose tissue followed by a $0.2 \mathrm{~cm}$ layer of thick skin. Patient's body, CBT, CND, glandular ratios and voxel size were kept the same as in MLO phantom. In both phantoms adipose and breast tissues are represented homogenous. Elemental compositions and densities are given in literature [15] - [17]. 
K. Karadžić, V. Karadžić, Estimation of mean glandular dose in mammography..., Rad. Applic., 2017, 2, 3, 200-203

\section{Simulation setup}

For the simulations, we used MCNPX version 2.7.0.

The x-ray source was mono-energetic photons with energies taking values as average energies of X-ray spectra for five different tube voltages: 25, 28, 29, 30 and $32 \mathrm{kV}$. X-ray spectra and average energies were calculated using SRS78 spectrum processor [19] for two anode/filter combinations $\mathrm{Mo} / \mathrm{Mo}$ and $\mathrm{Mo} / \mathrm{Rh}$ and are listed in Table 3. The distance from the source to the phantom was $60 \mathrm{~cm}$. Glandular ratios were 0.25 , 0.50 and 0.75 . In MLO simulations, angle projections were $30^{\circ}, 45^{\circ}, 60^{\circ}$ and $90^{\circ}$. The combination of these parameters gives 15 simulations for $\mathrm{CC}$ phantom and 60 simulations for MLO view. Number of particles simulated was $10^{\wedge} 7$.

Table 3. Average photon energies for different X-ray spectra

\begin{tabular}{|c|c|c|c|}
\hline $\begin{array}{l}\text { Tube } \\
\text { voltage } \\
(\mathrm{kV})\end{array}$ & Anode/Filter & Mo/Mo & $\mathrm{Mo} / \mathrm{Rh}$ \\
\hline 25 & \multirow{5}{*}{$\begin{array}{c}\text { Average } \\
\text { photon } \\
\text { energy }(\mathrm{keV})\end{array}$} & 15.6 & 16.6 \\
\hline 28 & & 16.1 & 17.2 \\
\hline 29 & & 16.3 & 17.3 \\
\hline 30 & & 16.5 & 17.5 \\
\hline 32 & & 16.8 & 17.7 \\
\hline
\end{tabular}

The F6 tally estimates the amount of energy deposited in the volume by the designated particle. The result is normalized by the mass of the volume and by the number of particles simulated and it is given in $\mathrm{MeV} / \mathrm{g}$. We used DE/DF card to incorporate G(E) function. The $\mathrm{DE}$ card defines energy bins in $\mathrm{MeV}$ while $\mathrm{DF}$ card defines values of $\mathrm{G}(\mathrm{E})$ as given by equation (1).

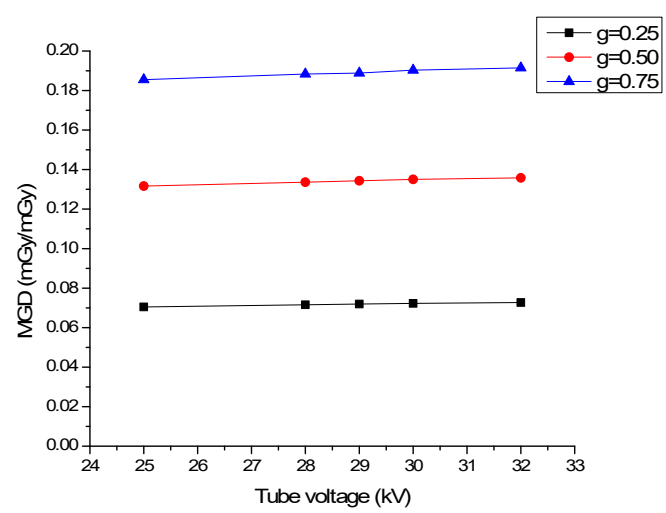

Figure 3. MGD for different tube voltages and different glandular ratios in $\mathrm{CC}$ view for Mo/Mo anode/filter combination

\section{RESULTS}

Tables 1 and 2 summarize the results of the simulations for MLO view. Results are the calculated values for MGD for three glandular ratios and for four angle projections for each glandular value for five different photon energies for two anode/filter combinations. MGD values for CC phantom are plotted in Figures 3 and 4. Three graphs represent MGD values for three different g-values plotted against five photon energies. Figure 5 represents linearity of MGD over glandular ratio. The MGDs are normalized by the entrance skin exposure, which is calculated beneath the compression paddle and at the top of the breast phantom without backscattering. The distance between the focal spot and the ESE point is $65 \mathrm{~cm}$.

\section{DISCUSSION}

From Tables 1 and 2, we can see that MGD is in the range from 0.026 to $0.144 \mathrm{mGy} / \mathrm{mGy}$ for MLO view for $\mathrm{Mo} / \mathrm{Mo}$ and from 0.031 to $0.143 \mathrm{mGy} / \mathrm{mGy}$ for Mo/Rh anode/filter combination. Projection angle play important role in MGD because it defines which portion of breast tissue, and by that the glandular tissue, is being irradiated. We simulated only positive angles since we modeled phantom to be symmetrical around $\mathrm{o}^{\circ}$. For CC view, we have MGD taking values from 0.07 to $0.191 \mathrm{mGy} / \mathrm{mGy}$ for Mo/Mo and from 0.072 to 0.193 for Mo/Rh anode/filter combination, as shown in Figures 3 and 4. Resulting values for MGD are lower than those previously reported [8], [9], [10]. The reasons for this are approximations and assumptions used in this work considering modeling of the phantom and source spectrum.

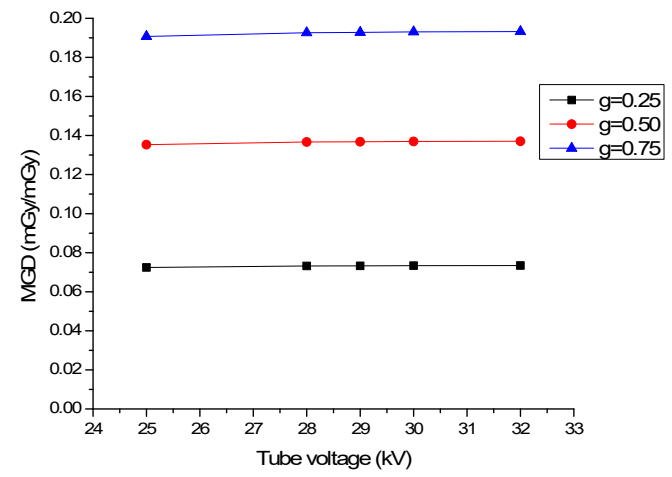

Figure 4. MGD for different tube voltages and different glandular ratios in $\mathrm{CC}$ view for Mo/Rh anode/filter combination

From the results we can see that for both MLO and CC there is an increase in MGD when glandular ratio is higher, which is in agreement with other published data [8]. The results in Figure 5 confirm the linearity of MGD over glandular ratio described in literature [4], [10]. Linearity is valid for all simulated energies as presented in Tables 1 and 2. Using the slopes of these lines, we can estimate MGD for different glandular ratios.

When comparing MGD from MLO and CC view, we can see that MLO projection gives lower doses than CC up to $18 \%$. This originates from the models in CC phantom where the breast tissue is positioned around central beam and being irradiated by highest photon fluence. On the other hand, in MLO view, photon fluence is reduced because of the heel effect. In 
K. Karadžić, V. Karadžić, Estimation of mean glandular dose in mammography..., Rad. Applic., 2017, 2, 3, 200-203

addition, pectoral muscle absorbs certain percentage of the dose which should have been absorbed by the breast tissue.

\section{CONCLUSION}

In order to estimate the mean glandular dose, we designed two voxel phantoms for two projections during mammography examination - MLO and CC. There is a slight deviation from the results published in literature due to approximations used for phantom modeling and source spectrum. Future work involves designing a more detailed phantom for improved MGD estimations.

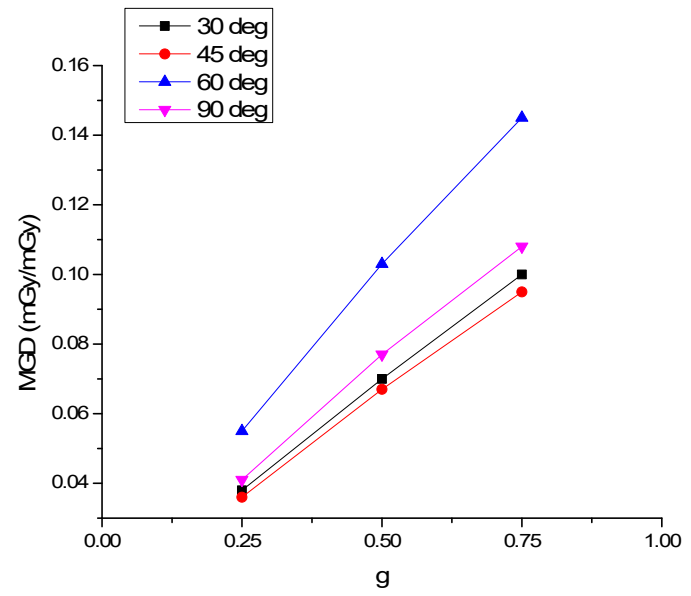

Figure 5. Linearity of MGD over glandular ratio for tube voltage of $28 \mathrm{kV}$ for Mo/Mo anode/filter combination

\section{REFERENCES}

1. K. Kerlikowske, D. Grady, S. M. Rubin, C. Sandrock and V. L. Ernster, "Efficacy of screening mammography. A meta-analysis," J. Am. Med. Assoc., vol. 273, no. 2, pp. 149 - 54, Jan. 1995.

DOI: 10.1001/jama.1995.03520260071035 PMid: 7799496

2. D. R. Dance, "Monte Carlo calculation of conversion factors for the estimation of mean glandular breast dose," Phys. Med. Biol., vol. 35, no. 9, pp. 1211 - 1219, Sep. 1990.

DOI: 10.1088/0031-9155/35/9/002

3. D. R. Dance, K. C. Young and R. E. van Engen, "Further factors for the estimation of mean glandular dose using the United Kingdom, European and IAEA breast dosimetry protocols," Phys. Med. Biol., vol. 54, no. 14, pp. 4361 - 4372, Jun. 2009.

DOI: $10.1088 / 0031-9155 / 54 / 14 / 002$ PMid: 19550001

4. J. M. Boone, "Glandular breast dose for monoenergetic and high-Energy x-ray beams: Monte Carlo assessment," Radiology, vol. 213, no. 1, pp. 23 - 37, Oct. 1999.

DOI: 10.1148/radiology.213.1.r99oc3923

PMid: 10540637

5. D. R. Dance et al., "Breast Dosimetry Using Highresolution Voxel Phantoms," Radiat. Prot. Dosim., vol. 114, no. 1-3, pp. 359 - 363, May 2005.

DOI: $10.1093 / \mathrm{rpd} / \mathrm{nch} 510$

PMid: 15933137
6. K. Bliznakova, Z. Bliznakov, V. Bravou, Z. Kolitsi and N Pallikarakis, "A three-dimensional breast software phantom for mammography simulation," Phys. Med. Biol., vol. 48, no. 22, pp. 3699-3719, Nov. 2003

DOI: $10.1088 / 0031-9155 / 48 / 22 / 006$ PMid: 14680268

7. A. K. W. Ma, S. Gunn, D. G. Darambara, "Introducing DeBRa: A detailed breast model for radiological studies," Phys. Med. Biol., vol. 54, no. 14, pp. 4533 4545, Jul. 2009.

DOI: $10.1088 / 0031-9155 / 54 / 14 / 010$

PMid: 19556683

8. L. Gholamkar, A. A. Mowlavi, M. Sadeghi and M. Athari, "Assessment of Mean Glandular Dose in Mammography System with Different Anode-Filter Combinations Using MCNP Code," Iran J. Radiol., vol. 13, no. 4, e36484, Oct. 2016.

DOI: 10.5812 /iranjradiol.36484

PMid: 27895876

PMCid: PMC5117115

9. A. K. W. Ma, A. Alghamdi, "Development of a realistic computational breast phantom for dosimetric simulations," Nucl. Sci. Thech., vol. 2, pp. 147 - 152, 2011;

DOI: $10.15669 /$ pnst.2.147

10. A. K. W. Ma, D. G. Darambara, A. Stewart, S. Gunn, E. Bullard, "Mean glandular dose estimation using MCNPX for a digital breast tomosynthesis system with tungsten/aluminum and tungsten/aluminum+silver $\mathrm{x}$ ray anode-filter combinations," Med. Phys., vol. 35, no. 12 , pp. $5278-5289$, Dec. 2008

DOI: $10.1118 / 1.3002310$

PMid: 19175087

11. I. Sechopoulos, S. Suryanarayanan, S. Vedantham, C. D'Orsi, A. Karellas, "Computation of the glandular radiation dose in digital tomosynthesis of the breast," Med. Phys., vol. 34, no. 1, pp. 221 - 232, Jan. 2007.

DOI: $10.1118 / 1.2400836$

PMid: 17278508

PMCid: PMC4280100

12. J. Zhang, B. Bednarz and X. G. Xu, "An Investigation of Voxel Geometries for MCNP-based Radiation Dose Calculations," Health phys., vol. 91, suppl. 2, pp. S59 S65, Nov. 2006.

DOI: 10.1097/01.HP.0000234039.58356.de PMid: 17023800

13. G. Verdú et al., "Mammographic Dosimetry Using MCNP-4B,” J. Nucl. Sci. Tech., vol. 37, suppl. 1, pp. 875 $-879,2000$.

DOI: $10.1080 / 00223131.2000 .10875015$

14. D. B. Pelotiwz, "MCNPX user's manual version 2.7.0," Los Alamos National Library, Los Alamos (NM), USA, Rep. LA-CP-11-00438, 2011.

15. G. R. Hammerstein et al., "Absorbed radiation dose in mammography," Radiology, vol. 130, no. 2, pp. 485 491, Feb. 1979.

DOI: $10.1148 / 130.2 .485$

PMid: 760167

16. J. H. Hubbell and S. M. Seltzer, "Tables of X-Ray Mass Attenuation Coefficients and Mass Energy-Absorption Coefficients," NIST, Gaithersburg (MD), USA, 2004. Retrieved from:

https://www.nist.gov/pml/x-ray-mass-attenuationcoefficients;

Retrieved on: Dec 20, 2016

17. Tissue substitutes in radioation dosimetry and measurements, ICRU Report 44, ICRU, Bethesda (MD), USA, 1989.

18. K. Cranley, B. J. Gilmore, G. W. A. Fogarty and L. Desponds, Catalogue of Diagnostic X-ray Spectra and Other Data, IPEM Report 78, IPEM, New York (NY), USA, 1997. 